\title{
Lazer, Esporte e Cidadania: debatendo a nova moda do momento
}

Marcelo Paula de Melo

Resumo: Este trabalho busca discutir criticamente possíveis relações entre as novas configurações das políticas de esporte e a dita promoção da cidadania. Quem promove essas políticas de esportes? Quais os projetos de esporte presentes nessas ações? O que se está entendendo por cidadania? Quais as relações entre o acesso às políticas de esporte e uma concepção ampliada de cidadania? Qual a implicação disso para o campo da Educação Física?

Palavras Chaves: Esporte, Políticas Públicas e cidadania.

Constantemente sabemos de programas de esporte, públicos ou privados, que estão contribuindo para o "resgate da cidadania" de crianças, jovens, adultos, idosos, portadores de necessidades especiais, jovens em conflito com a lei. Ou ainda ações solidárias que devolvem a "cidadania" a grupos sociais que em algum momento de sua vida a "perderam". Qualquer ação que "tire" os jovens da rua é resgate de "cidadania". Qualquer ação solidária como filantropia empresarial, ação caridosa de uma Igreja, ou mesmo as novas políticas esportivas de atletas famosos; tudo em nome da "promoção de cidadania".

O termo cidadania tornou-se auto-explicativo. Sua densidade conceitual, sua carga de enfrentamento a uma ordem desigual foi mimetizada num discurso sem conteúdo. Mesmo os atores e organismos que estão diretamente ligados à implementação do projeto neoliberal, que com suas ações contribuem para a precarização das condições de vida da maioria da população mundial, - por exemplo, o Banco Mundial e os grandes agentes do capital financeiro - também clamam por cidadania em seus documentos. Como se o seu convocar fosse suficiente para esclarecer seus sentidos e projetos políticos. Promover, resgatar, devolver a cidadania é sinônimo de prática "revolucionária". Mas nesse caso

* Mestre em Educação. Membro dos grupos de pesquisa Lazer e Minorias (EEFD/ UFRJ) e Coletivo de Estudos sobre Política Educacional (FE/UFF)

Movimento, Porto Alegre, v. 10, n. 2, p.105-122, maio/agosto de 2004 
não estamos falando da utopia de superação do capitalismo. Talvez pequenas melhorias para tornar suportável tal precarização.

Com a emergência de novos atores na formulação/ implementação dessas políticas podemos dizer que relação esporte, cidadania e políticas públicas se complexifica. Estamos falando do chamado "terceiro setor", que seria constituído por organismos na sociedade civil, como as Ongs, Fundações empresariais, Associações Filantrópicas e Beneficentes. Ao "terceiro setor" caberia a implementação de políticas públicas, já que tanto o Estado, quanto o mercado, no neoliberalismo mais radical, fracassaram, ao passo que a "sociedade civil"1 poderia ser mais eficaz que estes dois setores, por não estar presa ao autoritarismo, como o Estado, e não buscar o lucro, como o mercado, transmutando-se em uma espécie de terceira via (Bresser Pereira \& Grau, 1999).

É importante ter claro não apenas a fragilidade conceitual do termo "terceiro setor". Isso fica claro quando tenta apresentar a sociedade constituída de três "setores" estanques e independentes: a saber, o $1^{\circ}$ setor, constituído pelo Estado, onde se vivenciam as questões políticas; o $2^{\circ}$ setor, constituído pelo mercado, responsável pela economia; e por fim o chamado $3^{\circ}$ setor, responsável pelo que seus apologistas chamam de social.

Apontar que a falaciosa separação em setores é algo que não condiz com o real é simples e claro. O desafio é compreender como essa noção se articula com a implementação do projeto de sociedade neoliberal e também sua inserção política como estratégia de obtenção de consenso das massas no atual momento histórico.

Por conta disso, chamamos a atenção para relação entre o "terceiro setor" e as políticas públicas no contexto do capitalismo neoliberal, bem como sua vinculação com a noção de precarização, filantropização e focalização dessas políticas. Não obstante, sua vinculação orgânica com as propostas do Banco Mundial para as políticas públicas no contexto do chamado ajuste neoliberal não pode ser ignorada (Melo, 2003).

Não é difícil observar políticas esportivas (abarcadas pelo também genérico e auto-explicativo termo "projeto social") de organismos privados, como empresas, Ongs, Instituições

1 Como podemos notar ocorre uma apropriação vulgar do conceito de sociedade civil, desenvolvido por Gramsci, indicando uma "esfera" da sociedade sem conflitos e projetos de sociedade divergentes. Como se neste espaço as classes sociais também não estivessem em luta constante. Maiores informações ver Coutinho (2002) e Neves (2002).

Movimento, Porto Alegre, v. 10, n. 2, p.105-122, maio/agosto de 2004 
Filantrópicas, ou mesmo de órgãos públicos, voltados para essa "promoção da cidadania". Frente ao constante evocar da "dimensão cidadã" dessas políticas esportivas, debateremos as possíveis relações entre cidadania, esporte e lazer, e seus desdobramentos em programas públicos e/ou privados de esporte.

\section{Sobre cidadania}

Podemos dizer que o termo cidadania está na moda. Diversos exemplos da incorporação do termo ao cotidiano se apresentam. Não é raro sabermos de programas, ações, projetos que se arvoram promotores da cidadania.

Por outro lado, notamos uma perigosa homogeneização deste termo. Como aponta Bourdieu e Wacquant (2000) estamos diante de uma nova língua, uma nova vulgata planetária, onde estão ausentes palavras como: capitalismo, classes em luta, dominação, exploração de classe e tantos outros. E segundo tais autores, o efeito disso torna-se mais drástico e pernicioso por ser conduzido pelos partidários dos ajustes neoliberais, e também por alguns militantes outrora de esquerda, mas que hoje atuam na implementação do referido projeto. Assim, cidadania tornou-se um grande guarda chuva, evocada por atores e organismos de diversas matrizes políticas.

Diante disso, é urgente e necessário debater tal conceito recuperando sua vinculação com as lutas dos trabalhadores e movimentos contestatórios no âmbito do capitalismo, e com isso, compreender os diferentes projetos de sociedade presentes nas ditas "ações cidadãs".

Debater cidadania implica considerar sua interface com outro conceito que também parece ter perdido seu potencial contestatório do capitalismo. Estamos falando da estreita relação entre cidadania e democracia, sendo esta entendida, não apenas como sufrágio universal, indispensável, mas não suficiente. Entendemos a democracia como "... a presença efetiva das condições sociais e institucionais que possibilitam ao conjunto dos cidadãos a participação ativa na formação do governo e, em conseqüência, no controle da vida social" (Coutinho, 2000, p. 50). Portanto, estamos diante de um entendimento de democracia que não se restringe aos mecanismos procedimentais, como sufrágio universal, existência de parlamentos eleitos, direito á organização, mas que busca radicalizar tais mecanismos num projeto de sociedade de

Movimento, Porto Alegre, v. 10, n. 2, p.105-122, maio/agosto de 2004 
participação ampliada nos mecanismos de decisão, ou seja, articulando a socialização da participação e também dos mecanismos e aparelhos de poder.

Assim, consideramos a cidadania não como algo outorgada definitivamente, mas sim fruto de uma luta permanente, sobretudo das classes trabalhadoras visando a incorporação de direitos, em processos históricos de longa duração. Estamos falando da capacidade conquistada por todos os indivíduos e grupos sociais de disporem dos bens socialmente produzidos, possibilitando uma vida onde o acesso às criações artísticas, científicas, do plano da subsistência material não seja privado a pequenos grupos. Um regime democrático precisa contemplar todos os chamados direitos de cidadania (Coutinho, 2000).

Nesta linha, compreender as barreiras e desafios para esse acesso universal aos referidos bens produzidos historicamente, bem como os interesses de classes e grupo sociais divergentes nesse processo, podem nos fornecer ricos elementos para a discussão. Assim, deixa-se de abordar cidadania de maneira abstrata, sem lutas e conflitos divergentes, abstraído do processo de classes e grupos sociais em luta com interesses e projetos de sociedade que se embatem, gerando diferentes concepções e noções de cidadania.

Coutinho, partindo da proposta de T. H. Marshall de separação de direitos em civis, políticos e sociais, analisa o trajeto histórico de implementação ou não na ordem capitalista, bem como as lutas que o engendraram. ${ }^{2}$ Nessa linha, os chamados direitos civis, longe de serem direitos naturais, são conquistas históricas de uma classe - a burguesia - frente a outras - clero e a nobreza - na busca de limitar o poder do Estado Absolutista. Estamos falando do direito à propriedade, à liberdade de expressão, direito de ir e vir, direito à vida. Contudo, o rechaço a hipervalorização liberal dos direitos civis, não implica em desconsiderar sua importância. Estes não são dispensáveis, mas também não se bastam por si.

Quanto aos direitos políticos, tanto o sufrágio, como a organização dos trabalhadores, foram combatidas por liberais clássicos. Durante muito tempo, as mulheres e os trabalhadores foram proibidos de votar, por, supostamente, não terem autonomia,

2 Apenas para reforçar, Marshall traça uma trajetória que primeiro efetivaram-se os direitos civis, depois os políticos e por fim os sociais, analisando a Inglaterra. A despeito da linearidade e sua pouca relação com outras formações sociais, aceitaremos tal distinção para poder problematizar seu processo histórico no Brasil.

Movimento, Porto Alegre, v. 10, n. 2, p.105-122, maio/agosto de 2004 
dependendo de seus maridos ou pais e de seus patrões, respectivamente. O direito ao voto, como também o direito à organização sindical são conquistas dos movimentos de trabalhadores e outros movimentos contestatórios que não faziam parte do ideário liberal. A possibilidade de fazer parte da vida política como eleitor, ou mesmo influindo diretamente através de organizações como sindicatos, partidos de massas ou movimentos sociais são "invenções" das classes subalternas. São conquistas democráticas conseguidas contra e apesar da burguesia. Por isso, Coutinho (2000) aponta ser no mínimo uma impropriedade teórica e histórica chamar de burguesa uma democracia apenas formal visto que até isso foi conseguido com luta e contra o projeto político desta classe.

Por fim, no debate dos direitos sociais a possibilidade de afirmação da cidadania torna-se ainda mais difícil no âmbito do capitalismo. Estamos falando do acesso/permanência as políticas universais de saúde, educação, trabalho, assistência social, lazer transporte, entre outros. Nos países capitalistas centrais, durante o período do Estado de Bem-estar, os movimentos dos trabalhadores, a partir das lutas nos diversos sujeitos políticos coletivos, obtêm conquistas, aumentando sua rede de proteção social, ao passo que no contexto dos chamados países periféricos do capitalismo tal possibilidade esteve e está longe de se concretizar.

O acesso a tais direitos foram/são decorrentes das correlações de força entre as classes em lutas, e no contexto em que tal correlação era favorável às classes trabalhadoras nos países centrais, e nem tão desfavoráveis nos países periféricos, as possibilidades de acesso aos direitos sociais eram menos difíceis. Antes de considerar os direitos sociais apenas concessão do capital para manutenção da ordem capitalista, podemos vê-los como conquistas dos movimentos dos trabalhadores. Tanto é que estão sendo progressivamente atacadas pelo neoliberalismo, onde, por diversos fatores, a capacidade de mobilização e luta dos trabalhadores para um projeto de sociedade democrático enfrenta diversas barreiras, não apenas nos sujeitos políticos coletivos clássicos, como sindicatos e partidos, mas também nos novos como movimentos sociais.

O chamado fim da história, das ideologias, das utopias ainda se faz presente, assim como o pensamento único. Até mesmo na esquerda. Como aponta Ellen Wood (2003, p. 13) parte significativa dos intelectuais da esquerda, tem procurado novas formas de se relacionar com o capitalismo que não a contestação, “... quando

Movimento, Porto Alegre, v. 10, n. 2, p.105-122, maio/agosto de 2004 
não o abraçam como melhor dos mundos possíveis, limitam-se a sonhar com pouco mais que um espaço nos seus interstícios e prescrevem apenas resistências locais e particulares". ${ }^{3}$

O exercício da cidadania é amplamente dificultado pela formação social capitalista, radicalizada no atual contexto do neoliberalismo. Na medida em que os chamados direitos civis são constantemente subjugados, sendo a possibilidade de ir e vir algo que não existe em muitos bairros pobres do Brasil, bem como a liberdade de expressão, sem falar no direito à propriedade, inexistente para um universo significativo da população, destituído das condições objetivas de realizar tal direito. ${ }^{4}$

Quanto aos direitos políticos - a possibilidade de intervenção na vida política da sociedade, através do sufrágio, da atuação em conselhos, em sindicatos, movimentos sociais, em organismos de classe, mas não somente - a despeito das diversas ditaduras capitalistas ao longo do século XX, bem como possíveis fraudes e manipulações nos processos eleitorais, consideramos limitadas as reais possibilidades de participação política em um contexto de criminalização da contestação; de constantes ataques aos organismos representativos dos trabalhadores, como os sindicatos ainda combativos e movimentos sociais; e de privatização dos aparelhos de poder.

Nesse contexto, onde a disputa política pelo sentido das palavras também é constante, notamos uma certa "frouxidão" conceitual no debate de cidadania. Com isso, não é raro lermos em documentos do Banco Mundial, por exemplo, o evocar das chamadas ações cidadãs, bem como o clamor de que as medidas propostas (ou seriam impostas?) são aquelas que irão promover a cidadania e o desenvolvimento sustentável.

3 "No exato momento em que se necessita urgentemente de uma compreensão crítica do sistema capitalista, grandes seções da esquerda intelectual, em vez de desenvolver, enriquecer e refinar os instrumentos conceituais necessários dão amplos sinais de que pretendem abandoná-los" (WOOD, 2003, p. 13).

4 Isto pode ser observado no caso do direito à propriedade. O MST, por exemplo, parte de uma bandeira historicamente burguesa, no sentido de gênese, que é o direito à propriedade, só que o atendimento a tal bandeira, ou seja, universalizar tal direito é incompatível com a sociedade capitalista, que defende a apropriação por pequenos grupos não só da propriedade como também dos frutos do trabalho produzidos coletivamente.

5 Isto fica claro em dois documentos do Banco Mundial com os emblemáticos títulos: "O Estado em um mundo em transformação", de 1997: "Do Confronto à títulos: "O Estado em um mundo em transformaçãã", de 1997; "Do Confronto à de 2000, disponíveis no sítio www. bancomundial.org.br
de

Movimento, Porto Alegre, v. 10, n. 2, p.105-122, maio/agosto de 2004 
Como lembra Arantes (2000, p. 03), tudo vira luta por cidadania, incorporação de direitos, fortalecimento da sociedade civil, espaços de interação, compromisso e participação cidadã. Atentar para um "mimetismo terminológico" que confunde e educa para um perigoso consenso incapaz de compreender os diferentes projetos de sociedade expressos sob uma aparente homogeneidade terminológica é relevante sob pena de sermos envolvidos nessa onda.

\section{Esporte, lazer e nova cidadania}

Relacionando esporte e cidadania, não é difícil sabermos de políticas de esporte, sejam públicas ou privadas, sobretudo em bairros pobres que se autodenominam como promotoras de cidadania. Além disso, é comum o debate da relação entre Educação Física escolar e cidadania.

Diferente de outras épocas, hoje é quase senso comum acadêmico a noção de que políticas esportivas e as aulas de Educação Física escolar que objetivem a formação de novos talentos, pautadas nos códigos do esporte de rendimento, representam um grande retrocesso. Isto se relaciona com o projeto esportivo e de Educação Física já amplamente criticado no âmbito da Educação Física. E na busca de novos paradigmas para legitimar tais ações, atrela-se no discurso a relação entre Educação Física, lazer, esporte e cidadania. A despeito de exceções pontuais, em geral pouco se fala em descobrir novos campeões. Não mais formar atletas, e sim formar cidadãos.

Mas qual a concepção de cidadania está em questão? Quais os seus limites e possibilidades no sentido de um projeto de sociedade radicalmente democrático? Quais os riscos dessa relação? Tal debate se faz urgente face ao seu crescente convocar em nossos dias.

No âmbito da Educação Física um autor que logrou discutir mais detalhadamente sua relação com a cidadania foi Mauro Betti (1999). Assim, entende cidadania como direito a ter direitos, sem com isso explicitar qual classe ou grupo social terá direitos, nem quais direitos são esses, bem como a não problematização dos interesses conflitantes para efetivação desses direitos. Não obstante pensamos ser no mínimo um equívoco histórico de Betti (p. 84-85)

6 O capitão do tetra, Dunga, quando perguntado sobre os objetivos da prática esportiva no Instituto Dunga de Desenvolvimento do Cidadão, foi enfático em declarar que eles trabalham "inclusão social, gerando oportunidades e formando os cidadãos do futuro" (GLOBO, 2002, p. 14).

Movimento, Porto Alegre, v. 10, n. 2, p.105-122, maio/agosto de 2004 
conceber que os direitos civis e políticos foram obtidos no século XIX, bem como tratar abstratamente o acesso aos direitos sociais no século XX, sem explicitar que tal realidade se aplica apenas aos países capitalistas centrais, e mesmo assim, apenas durante os chamados anos dourados do capitalismo.

Relacionando cidadania com democracia, Betti afirma que aquela também pode ser entendida como a "... criação de espaços sociais de luta (movimentos sociais) e definição de instituições para a expressão política (partidos, órgãos públicos), visando à consolidação de direitos" (p. 85). Nesse ponto, podemos dizer que estamos diante de fenômenos diferentes, visto que a referida criação daqueles espaços, assim como a emergência dessas novas formas de expressão política, articulam-se com o processo de socialização da participação política que seria a emergência das massas como atores políticos, fazendo-se representar através de diversos organismos como partidos de massa, jornais, sindicatos, além de movimentos de diversas ordens.

Contudo, partindo do conceito de sociedade civil em Gramsci, podemos apontar que a burguesia e suas frações também se organizam no dito "espaço público", sendo também espaço da luta de classes pela direção da sociedade, e não apenas "reino" dos movimentos contestatórios. Com isso, queremos nos contrapor a uma tendência comum de considerar a sociedade civil espaço por si de enfrentamento do capitalismo, como se em seu interior não se fizessem presentes movimentos e organismos diretamente articulados com projetos de sociedade antidemocráticos, como no atual momento histórico.

A emergência desses espaços e a criação/emergência desses organismos não garantem, por si, maiores avanços quanto aos direitos de cidadania e ampliação da democracia. Tais processos possibilitam ampliar a luta política, divulgando concepções de mundo e projetos de sociedade através do que Gramsci (2001) chamou de aparelhos privados de hegemonia, ou organismos de adesão voluntária que estão na sociedade civil, atuando como intelectuais coletivos de cada classe. Isso implica em considerar, que a burguesia, em suas mais variadas frações, também se organiza na sociedade civil, através de seus partidos, movimentos sociais, organismos de classe, mídia, objetivando difundir seus projeto de sociabilidade.

Objetivando discutir o que seria uma Educação Física cidadã, Betti apresenta três princípios para o debate: os princípios da

Movimento, Porto Alegre, v. 10, n. 2, p.105-122, maio/agosto de 2004 
inclusão, da alteridade e da formação e informação plenas (p. 8687). Sobre a inclusão, reconhecendo o histórico excludente da Educação Física no Brasil, o autor propõe mecanismos pedagógicos para que a possibilidade de vivência da Educação Física seja para todos os alunos, não bastando que estes estejam na Escola. Quanto à alteridade, Betti, clama pelo tratamento pedagógico que considera o aluno um ser social e não apenas um objeto, ou ser biológico, algo comum em nossa área. Por fim, quanto à formação e informação plena, acertadamente Betti cobra por mais especificação de um discurso comum na área: que a Educação Física promove a "formação integral dos educandos", por aliar as dimensões físicas e intelectuais, além de afetivas. Explicitando como tal formação integral pode acontecer, termina dizendo serem essas as "contribuições da Educação Física para a construção da cidadania, crítica democrática e participativa" (1999, p. 88).

A partir destes três princípios, podemos notar uma certa aproximação da condição de cidadão à condição de aluno, ou seja a Educação Física cidadã seria aquela que acontece na Escola. Fora da Escola, as possibilidades da Educação Física/esportes contribuírem nesse processo de ampliação da cidadania não foram problematizadas pelo autor, embora ao fim debata a relação mídia, esportes e Educação Física. Neste ponto, seria relevante um debate acerca do acesso/permanência ao esporte como direito social e sua relação com a cidadania.

Arroyo (2001) aponta que algumas vezes "sofremos" de um processo de escolacentrismo, sem com isso relacionar a Escola com a totalidade da dinâmica da sociedade. Isso não implica em desmerecer ou mesmo desqualificar o papel da Escola em nossos dias, apenas alertar para o fato de que o processo de formação de sujeitos, de cidadãos é um processo que passa pela escolarização, mas se esgota nela, e que "... a construção de sujeitos sociais, cidadãos, sujeitos humanos é algo muito mais complexo e que a Escola é, às vezes, uma gota d'água nessa complexidade. E não quer dizer que esta gota d'água não seja fundamental" (p. 276).

Por isso, as relevantes considerações de Betti apresentam limites quando aborda a relação Educação Física e cidadania, por não problematizar o modismo da cidadania em nosso tempo, algo muito próximo das políticas de esporte, em geral fora da Escola, embora nesta também. Não obstante, ao abordar tal questão a partir das relações professor-aluno, no caso do princípio da alteridade, ou a partir dos objetivos da Educação Física na Escola, no caso do princípio da formação/informação plena, bem como pelo binômio inclusão/

Movimento, Porto Alegre, v. 10, n. 2, p.105-122, maio/agosto de 2004 
exclusão a partir das aulas de Educação Física, Betti opta por fazer tal debate apenas no plano micro, ou seja, no âmbito da prática pedagógica no "chão da Escola". Longe de desconsiderar a priori a relevância deste debate, pensamos que abstrair o debate da cidadania dos projetos de sociedade das classes em luta - isto não significa que as práticas pedagógicas cotidianas dos docentes nas escolas e fora delas não se pautem em projetos de sociedade, mesmo quando não estão claros para os envolvidos-, implica em não questionar as próprias bases que geram as barreiras para a efetivação do que Betti chamou de Educação Física cidadã. Aliás, fica a pergunta se é possível haver uma Educação Física cidadã num mundo onde o exercício da cidadania seja restrito a poucos.

No que tange às novas políticas esportivas, sejam públicas ou privadas, e sua vinculação com a dita "promoção da cidadania", temos notado um grande incremento tanto no número de programas quanto na divulgação dos mesmos na sociedade. Seja em programas de televisão, em propagandas na grande mídia ou mesmo com a produção de cadernos informativos sobre as novas "ações cidadãs" a partir do esporte, têm obtido grande destaque na sociedade.

Sem desconsiderar a importância do lazer na vida em sociedade, e considerando que a condição individual e social de ser cidadão passa pelo acesso/permanência a várias formas de vivenciar este lazer, pensamos ser no mínimo apressado afirmar que "vivência do lazer pode ser compreendida como o próprio exercício da cidadania" (Linhales, 1999, p. 27). Nesta linha, pensamos que o exercício da cidadania passa pela vivência do lazer, mas não se limita a ele. E sendo, como a própria autora aponta, o lazer um tempo/ espaço de reflexão relativo a normas e valores que fundam a sociabilidade na sociedade em que estamos inseridos, possibilitando reorganizar criticamente a estrutura social, em seu interior também podem ser dar vivências lúdicas que objetivam a não reflexão ou mesmo a legitimação/naturalização dos valores e normas que regem a sociedade. Por isso, a vivência do lazer, e dos esportes, podem relacionar-se não com um projeto de sociedade democrático, mas sim com a manutenção do atual estados de coisas.

A metáfora utilizada por Linhales (1999, p. 27) “lazer inexistente", como maneira de expressar vivências lúdicas no lazer com conotação mercadorizada e espetacularizada, é no mínimo pouco esclarecedora. Na lógica da sociedade capitalista em sua fase neoliberal, tal modelo de vivenciar o lazer não é algo extraordinário 
ou mesmo contraditório, e sim expressão das manifestações dessa concepção de mundo no que tange ao lazer. Assim, é só assim, faz sentido a aproximação do termo, não do conceito, cidadania com práticas de lazer no âmbito de relações sociais marcadas pela égide capitalista.

Diversos exemplos dessa nova concepção que reúne esporte e cidadania se apresentam. O pulular de Fundações de esportistas, empresariais, de Ongs se inserem no bojo das estratégias de consolidação do chamado "terceiro setor". O lazer e os esportes não ficam de fora dessa nova onda de "ações cidadãs", ou como aponta a Veja (2001), da ação desses "Gigantes do Bem". Não por acaso temos notado um grande incremento de programas na grande mídia visando divulgar tais "ações cidadãs".

A proposta "pedagógica" desse movimento não pode ser minimizada. A disseminação das noções de "empresa social", "responsabilidade social das empresas", "empresa cidadã"; "empresa amiga da criança" representa uma proposta política que concebe o grande capital, financeiro e industrial, como os novos mecenas do social, em detrimento de um Estado que não cumpriria nem suas obrigações, independente das razões. Como estratégia de obtenção de consenso nada mais apropriado à intensa divulgação midiática das ações sociais empresarias, assim como a criação de diversos institutos de grandes empresas, responsáveis por profissionalizar e politizar a velha filantropia empresarial.

Nesse debate do "terceiro setor" e políticas públicas, notamos uma perigosa e emblemática tendência de "despolitização" da política. Na verdade totalmente politizada, mas para uma suposta neutralidade, e não conflitualidade, como se não houvesse interesses e projetos de sociedade que levassem a essas situações,

7 Numa rápida pesquisa nos meios de comunicação encontramos as seguintes Organizações: Instituto Ayrton Senna, Instituto Guga Kuerten, Instituto Dunga de Desenvolvimento do Cidadão: Instituto Beneficente Romário de Souza Farias de Desenvolvimento do Cidadão; Instituto Beneficente Romario de Souza Farias (Romário); Instituto Bola pra frente (Jorginho e Bebeto); Instituto Ronaldinho; Fundação Gol de Letra (Raí e Leonardo); Fundação Cafu, Fundação Jackie Silva (Jaqueline - Vôlei de Praia). Grande parte dos parceiros dessas organizações são grandes empresas nacionais e multinacionais, além de alguns órgãos estatais federais, estaduais e municipais.

8 O Jornal "O Globo" do Rio de Janeiro publica mensalmente um caderno cujo título é emblemático: "Razão Social - O Espaço da Empresa Cidadã". Neste caderno são apresentados os programas filantrópicos do grande capital, bem como importância disso na importância disso na atual conjuntura. I na capa uma foto de tetraçampeão de futebol Bebeto, com o subtítulo: "Está $n$ Hora de Virar Este Jogo: Idolos do Esporte Usam Prestígio para Criar ONGs e Fundações de Auxílio a Pessoas Carentes".

Movimento, Porto Alegre, v. 10, n. 2, p.105-122, maio/agosto de 2004 
cuja solução passa por repensar a dinâmica societária e não apenas pela mobilização de "indivíduos caridosos".

O próprio termo despolitizar a política indica um certo "esquerdacentrismo" de nossa parte. Como se fazer política significasse apenas ações contestatórias. A direita faz política o tempo todo e a suposta despolitização é a política de dominação que tem funcionado há tempos. Rever nossos conceitos também pode servir como importante estratégia de luta.

Partindo de um consenso na sociedade que a prática esportiva carrega em si elementos positivos para formação das novas gerações, um grande movimento de promoção dessas políticas esportivas de ex-atletas e/ou do grande capital se apresentam como os redentores sociais com a difícil tarefa de "resgatar a cidadania" de jovens e crianças. Estamos diante dos chamados projetos sociais, geralmente localizados em bairros pobres e violentos, que muitas vezes se apresentam como a única possibilidade de acesso para muitos jovens. Talvez por isso, goze de maior prestígio social, indicando uma prática que contribua para as novas gerações.

Curiosamente apresentam-se para "resgatar a cidadania" de jovens, crianças e adultos, principalmente nos bairros pobres. Contudo, cabe a problematização: como resgatar algo que jamais existiu? Talvez caiba conquistar, inventar, mas resgatar algo que jamais houve é no mínimo equivocado, além de tentar camuflar-se embaixo desse grande "guarda chuva cidadão".

Nesse ponto, a questão não é execrar ou louvar a esses programas a partir de um paradigma moral. O desafio que se apresenta é compreender a matriz política dessas ações, e inventar táticas e estratégias de enfrentamento/resistência sejam no plano micro, a partir das relações pedagógicas que ocorrerão nesses espaços, mas também no plano macro do debate de projetos políticos de sociedade. Talvez seja hora de nos perguntarmos qual o projeto de sociedade que pode estar presente num programa financiado pelo grande capital. Qual o grau de autonomia que dispõem os profissionais para implementarem ações contrárias a que esperam seus financiadores, o que implica em último caso criticar o próprio financiador? O que tem levado ao capital a investir em ações sociais? Por quê o esporte e o lazer?

9 Devo este alerta a Carlos Henrique Santos Martins, que questionou minha não problematização desta questão em meu texto.

Movimento, Porto Alegre, v. 10, n. 2, p.105-122, maio/agosto de 2004 
Inegavelmente, os esportes e as artes possibilitam novas formas de relação com o mundo, sendo tais manifestações parte integrante de um projeto de melhorias das condições gerais de vida. Contudo, o caráter de redentor da cidadania perdida em outros momentos, e o aproveitamento político disso como forma de obtenção de consenso, não pode ser desprezada. Não se trata de desconsiderar a importância disso para a vida das pessoas que estão sendo atendidas, já que para essas, num contexto de poucas opções de lazer, pouco importa quem promove, se é o Estado, uma Ong, ou um candidato a cargo político, ou já eleito visando ampliar/ consolidar sua base política. O desafio é compreender os aspectos políticos disso, e sua vinculação/capacidade de dar conta das metas que se propõe a atender. Podemos perguntar se a prática esportiva por si é garantidor de cidadania, ou ainda se está relacionada com o processo de conquista/ampliação da mesma. Ou então se podemos resgatar a cidadania num contexto em que, apesar do as novas opções de lazer, os antigos problemas continuam, senão se agudizaram.

Por outro lado, também notamos um certo revolver de justificativas conservadoras ao abordar a importância das políticas públicas de esporte. Nos anos 1990 com um avanço da pobreza e uma maior visibilidade da violência urbana credita-se ao esporte o papel de redentor da juventude pobre. Além disso, também a tarefa de controlar os impulsos e promover uma sociabilidade civilizada. Isso fica claro quando Gonçalves, em seu trabalho sobre a Vila Olímpica da Mangueira, aponta que

As tentativas de desenvolvimento de um'etos civilizador' que afaste ojovem dessa realidade hostil, permitindo a implementação de práticas sociais que propiciem uma sociabilidade afirmativa e ampliem as possibilidades de participação desse jovem na sociedade, contribuem para a construção de uma cidadania plena, garantindo assim a saúde da coletividade" (2003, p. 53. Grifo nosso).

As políticas públicas de esporte "precisariam" de outras justificativas que não apenas democratização do acesso/ permanência. Não é difícil ouvir assertivas de que o jovem que pratica esporte não se envolve com drogas; ou argumentos mais conservadores no que tange ao tempo livre, como sendo estes a raiz de todos os males e problemas da juventude; "não tem tempo de pensar besteira"; "não fica fazendo o que não deve na rua": "mente vazia oficina do diabo".

Movimento, Porto Alegre, v. 10, n. 2, p.105-122, maio/agosto de 2004 
Por trás de argumentações como estas, estão presentes componentes que há muito marcam algumas iniciativas que atendem os jovens pobres. Percebemos claramente a posição de que o jovem se envolveria com o crime por não ter outras coisas a fazer, indicando uma suposta linearidade entre falta de opções de lazer com o ingresso no mundo do crime, além de estabelecer uma espécie de relação causa/conseqüência. Assim, o esporte seria o "antídoto" perfeito para coibir tais práticas, uma espécie de analgésico social, sempre numa perspectiva conservadora de controle social. ${ }^{10}$

Programas de esporte, per si, não darão conta da resolução de todos os problemas sociais. Aliás, o esporte não pode ser tratado como a solução de problemas que requerem ações de ordem políticas muito mais incisivas do que simplesmente a criação de programas esportivos. A não ser que se pretenda justamente o contrário: o ocultamento da real gênese desses problemas que, supostamente, está se tentando enfrentar. Isso fica claro quando Gonçalves (2003, p. 143), que passa grande parte de seu trabalho sobre a Vila Olímpica da Mangueira sem posicionar-se acerca das declarações nesse sentido, aponta que com o aumento da criminalidade, da violência, junto á crise econômica, que atinge de maneira drástica os jovens, sobretudo pobres, surgem os chamados projetos sociais nos bairros pobres. Parece que, a despeito de pulular de iniciativas e de propagandas redentoras, a capacidade de respostas desses não é a mesma que a alardeada, já que tanto os problemas que serviram de justificativas para o desenvolvimento desses programas quantos as soluções criadas para resolvê-los continuam em vigor até hoje. Tudo sob a alcunha de "atuação cidadã".

10 Essa visão está presente nas concepções que buscam fundamentar as políticas públicas de esporte da Prefeitura Municipal do Rio de Janeiro. Como podemos ver no texto comentando sobre a importância da Vila Olímpica da Maré. "Na Vila Olímpica da Maré podemos destacar o fato da adesão escolar que representa uma porcentagem considerável e ainda, o estudo feito do envolvimento dos jovens da Maré em atos infracionários. Contamos que, dos jovens infratores do Complexo da Maré que deram entrada na $2^{\mathrm{a}}$ Vara da Infância e Adolescência no período de maio a novembro de 2001 , apenas $11 \%$ pertencem a comunidade da Maré, Baixa do Sapateiro e Morro do Timbal, que são as comunidades onde se encontra a grande maioria dos alunos matriculados no projeto, e os mesmos estão na faixa etária dos 17 anos, o que não condiz com a faixa etária dos alunos da Vila etária dos 17 anos, o que não condiz com a faixa etária dos alunos da Vila Olímpica, que é de 7 a 14 anos" Disponível em www.rio.rj.gov.br/smel. Tão grave parece ser o fato de louvar o fato dos jovens em conflitos com a lei estarem acima da idade dos freqüentadores da Vila Olímpica, o que posso afirmar não ser verdadeiro, visto que muitos jovens nesta idade são freqüentadores regulares da Vila.

Movimento, Porto Alegre, v. 10, n. 2, p.105-122, maio/agosto de 2004 


\section{Seguindo na luta}

À guisa de conclusão, podemos apontar que no campo das políticas de esporte, públicas ou privadas, a relação com a cidadania é algo volátil, sendo muitas evocadas por atores e organismos de diferentes matrizes e projetos políticos.

Concebemos o acesso/permanência a práticas corporais como dimensão da cidadania, por relacionar-se com a tarefa de socialização da produção humana e não com a apropriação privada ou por pequenos grupos da produção de riquezas, seja material ou cultural. A Educação Física e os esportes se inserem no campo dos bens culturais, indispensáveis a condição de ser cidadão, embora não suficientes. Com isso, o constante evocar de ações cidadãs nesse campo podem estar indicando um esvaziamento da dimensão política da cidadania de enfrentamento da ordem excludente do capitalismo. Assim, de bandeira de luta contra a organização excludente da sociedade capitalista, objetivando denunciar o acesso/ permanência desigual aos bens produzidos pela humanidade, bem como sua apropriação privada, a cidadania torna-se simples palavreado vazio.

Se reduzirmos a existência humana ao campo do possível, do imaginável, poderemos dizer que tais ações são melhores que nada, instituindo uma cultura do "pelo menos". Sem dúvida, são melhores que nada, mas reduziremos a dimensão da cidadania apenas ao campo do possível? Sonharemos e lutaremos apenas por um mundo possível?

Nesse sentido, concordamos com Carlos Nelson Coutinho (2000) de que o debate das organizações públicas não estatais/ terceiro setor como bastióes da democracia significa o coroamento da pequena política. E se recuperarmos a distinção que Gramsci fazia de pequena política para grande política podemos compreender bem o papel político dessas organizações em nosso tempo.

Gramsci (2000, p.21), ao trabalhar a referida distinção, aponta que a grande política refere-se aos assuntos ligados ao surgimento de novos Estados, ou à luta pela sua destruição, "pela conservação de determinadas estruturas orgânicas econômico-sociais". Neste caso, estamos diante de questões afeitas à própria organização da sociedade, e que os acontecimentos e luta pela mudança dos mesmos passa pela efetivação de uma nova ordem, uma vez que na atual, tal possibilidade não estaria contemplada.

Movimento, Porto Alegre, v. 10, n. 2, p.105-122, maio/agosto de 2004 
Por outro lado, no que tange à pequena política podemos dizer serem as questões menores, cotidianas, de pequena abrangência política, apresentando-se "no interior de uma estrutura já estabelecida em decorrência de lutas pela predominância entre as diversas frações de uma mesma classe" (Gramsci, 2000, p. 21).

Reduzir questões que envolvem toda a organização social a apenas pequenas disfunções organizacionais, como o debate do chamado "terceiro setor", é fazer pequena política. Mas, afirma Gramsci que não existe maior luta no plano da grande política do que tentar reduzir tudo a pequena política, como fazem os apologistas das organizações públicas não estatais/terceiro setor. Assim, de pequena e inocente esta política não tem nada, e sim é parte de um projeto de organização da sociedade, visando à ampliação e a conservação do atual estados de coisas.

Concordamos com Coutinho (2000, p. 67) quando diz que a luta pela ampliação do acesso/permanência aos direitos de cidadania choca-se com a lógica de acumulação capitalista, mas que não devemos ver essa contradição como antitético. Por isso, notamos um processo sinuoso de avanços e retrocessos, onde o capital recusa, resiste, e "é forçado a fazer concessões, sem nunca deixar de tentar instrumentalizar a seu favor (ou mesmo suprimir como atualmente) os direitos conquistados".

Nessa linha, a luta pela existência de políticas públicas de esportes e lazer com acesso universal a toda produção cultural da humanidade se apresenta como importante bandeira democrática. Investir nessa, e também em outras lutas, implica em questionar a possibilidade de atendimento no âmbito de uma formação social pautada pela lógica do lucro, do consumo de pequenos grupos, como tem sido a marca da sociedade capitalista. Por isso, mais do que possível, seja urgente e necessário à luta pela construção de uma outra sociedade e lembrar que esta sociedade será construída por homens e mulheres, onde possamos fazer valer a máxima escrita por Marx e Engels (1998, p. 44) no Manifesto Comunista: “no lugar da sociedade burguesa antiga, com suas classes e antagonismos de classes, teremos uma associação, na qual o desenvolvimento livre de cada um é a condição para o desenvolvimento de todos".

Apesar de reconhecermos as limitações impostas pela conjuntura não podemos ser partidários de posturas imobilistas, que ao invés de considerarem a adversidade do contexto visando sua superação, produzem análises que não perspectivam a possibilidade da superação, e sim inexorabilidade do sistema. Diante 
disso, nos parece ser urgente retomar o alerta de Antonio Gramsci (2001) de que o pessimismo da inteligência precisa vir acompanhado pelo otimismo da vontade, para que assim possamos pensar em possibilidade de construção de uma nova sociedade. Assim, quem sabe, nossas pesquisas consigam realmente estarem grávidas de alegria, vontade e riqueza teórica visando à superação do capitalismo, e lembrar que esta superação terá de ser feita pelas mulheres e homens, nos sujeitos políticos coletivos dos trabalhadores nos diversos espaços e momentos de lutas.

\section{Ócio, Deporte y Ciudadania: debatiendo la nueva moda del momento}

Resumen: Este trabajo pretende discutir de forma crítica las posibles relaciones entre las nuevas configuraciones de las políticas de deportes y la llamada promoción de la ciudadaniai Quién promueve esas políticas de deportes? ¿Cuáles son los proyectos de deportes presentes en esas acciones? ¿Qué se entiende por ciudadania? ¿Cuáles son las relaciones entre el acceso a las políticas de deportes y una concepción amplia de ciudadania? ¿Cuáles son las implicaciones para el campo de la Educación Física?

Palabras claves: Deportes, Políticas Públicas y Ciudadania.

Leisure, Sports e Citizenship: talking about the new
hype
Abstract: This work has the purpose of providing a
critical discussion about the new configuration of the
politics of sports and the " announced" citizenship
promotion. Who promotes these politics of sports?
Which projects can be observed in these actions?
What is the present meaning of citizenship? Which
are the connexions with the access of these politics
and an amplified conception of citizenship? What is
the importance of this theme for Physic Education?
Keywords: Sports, Publics Politics and Citizenship.

\section{Referências}

ARANTES, P. E. Esquerda e direita no espelho das ONGs. In: Cadernos ABONG $n^{\circ} 27$, p. 03-27, Mai/2000.

ARROYO, M. Educação em tempos de Exclusão. In: FRIGOTTO, G. \& GENTILI, P. A Cidadania Negada: Políticas de Exclusão na Educação e no Trabalho. São Paulo: Cortez, 2001, p. 270-279

Movimento, Porto Alegre, v. 10, n. 2, p.105-122, maio/agosto de 2004 
BETTI, M. Educação Física, Esporte e Cidadania. Revista Brasileira de Ciências do Esporte, Vol, 20, n. ${ }^{\circ} 2$ e 3, p. 84-92, 1999.

BOURDIEU, P. \& WACQUANT, L. A nova vulgata Planetária. MOVIMENTO/UFF, Niterói, n.2, p. 161-167, Set/2000.

BRESSER PEREIRA, Luiz Carlos \& GRAU, Nurria Cunnil. Entre o Estado e o mercado: o público não-estatal. In: _._. (Orgs.). O público não estatal na reforma do Estado. São Paulo: FGV; 1999. p. 15-48.

COUTINHO, C. N. A democracia na batalha das idéias e nas lutas políticas do Brasil de hoje. In: SEMERARO, G \&. FÁVERO, O. (Orgs.) Democracia e construção do público no pensamento educacional brasileiro. Petrópolis: Vozes, 2002, p.1140.

COUTINHO, C. N. Contra a Corrente: Ensaios Sobre Democracia e Socialismo. São Paulo: Ed. Cortez; 2000.

GONÇALVES, Maria Alice Rezende. A Vila Olímpica da Verde-e-Rosa. Rio de Janeiro; FGV, 2003.

GRAMSCI, A. Cadernos de Cárcere. Maquiavel e notas sobre o Estado e a Política. Vol. 3. Rio de Janeiro; Civilização Brasileira, 2000.

JORNAL O GLOBO. RAZÃO SOCIAL, O espaço da empresa cidadã. 02 de agosto de 2003.

LINHALES, Meily Assbú. Lazer, Cidadania e qualidade de vida: reflexões acerca da possibilidade de liberdade e de ação política. Licere, Belo Horizonte, v.2, n.1, p.19-30, 1999

MARX, Karl \& ENGELS, Friedrich. O Manifesto Comunista. 6. Ed. São Paulo: Paz e Terra, 1998.

MELO, M. P. Estado e Sociedade Civil em Tempos Neoliberais: discutindo o Terceiro Setor. In: Seminário Nacional Região Metropolitana: Governo, Sociedade e Território, São Gonçalo, UERJ/FFP/DGEO, 2003. Anais...

NEVES, Lúcia Maria W. (org.) O empresariamento da educação: novos contornos do ensino superior no Brasil dos anos 1990. São Paulo: Xamã, 2002.

VEJA, Edição Especial. Guia para fazer o bem. Editora Abril, dezembro de 2001.

WOOD, E. M.. Democracia contra capitalismo: a renovação do materialismo histórico. São Paulo: Editora Boitempo, 2003. 